\title{
First Epidemiological Analysis of Breast Cancer Incidence and Tumor Characteristics after Implementation of Population-Based Digital Mammo- graphy Screening
}

Erste epidemiologische Analyse der Brustkrebsinzidenz und der Tumorcharakteristika nach Implementierung des populationsbezogenen digitalen Mammografie-Screening-Programms

Autoren

Institute
S. Weigel ${ }^{1}$, W. U. Batzler ${ }^{2}$, T. Decker ${ }^{3}$, H. W. Hense $^{4}$, W. Heindel ${ }^{1}$

Institut für Klinische Radiologie und Referenzzentrum Mammographie Münster, Universitätsklinikum Münster Epidemiologisches Krebsregister, NRW

Gerhard-Domagk-Institut für Pathologie und Brust-Screening-Referenzpathologie, Universitätsklinikum Münster

Institut für Epidemiologie und Sozialmedizin, Universität Münster

\author{
Key words \\ - breast \\ - mammography \\ - digital mammography \\ screening \\ - breast cancer incidence rate \\ - cancer registry
}

eingereicht 29.7.2009

akzeptiert 18.9.2009

Bibliografie

DOI http://dx.doi.org/10.1055/ s-0028-1109831

Online-Publikation: 26.10.2009

Fortschr Röntgenstr 2009; 181:

1144-1150 @ Georg Thieme

Verlag KG Stuttgart · New York .

ISSN 1438-9029

Korrespondenzadresse

Dr. Stefanie Weigel

Univ.-Prof. Dr. Walter Heindel Institut für Klinische Radiologie, Universitätsklinikum Münster Albert-Schweitzer-Straße 33 48129 Münster

Germany

Tel.: ++49/251/8345650

Fax: $++49 / 251 / 8345660$ weigels@uni-muenster.de

heindel@uni-muenster.de

\section{Zusammenfassung}

$\nabla$

Ziel: Epidemiologische Evaluation des digitalen Mammografie-Screenings hinsichtlich Brustkrebsinzidenz und Tumorcharakteristika.

Material und Methoden: Mit Daten des Krebsregisters wurde die Implementierungsphase der beiden ersten digitalen Screening-Einheiten Deutschlands in der Regelversorgung hinsichtlich Inzidenzraten und Tumorcharakteristik analysiert. In der Region Münster/Coesfeld/Warendorf wurden von 10/2005 - 12/2007 74\% der 50 - 69Jährigen erstmals zum Screening eingeladen (Teilnahmerate 55\%, $\mathrm{n}=35961$ ).

Ergebnisse: 2002-2004 lag die mittlere Brustkrebsinzidenz (pro 100000) bei 297,9. Seit Programmetablierung stieg die Rate auf 532,9 (2007). Von 349 eingeschlossenen Screeningkarzinomen waren $76 \%$ invasiv $(265 / 349)$, außerhalb des Programms im gleichen Zeitraum 90\% (546/608). $37 \%$ der invasiven Screeningkarzinome (97/265) waren $\leq 10 \mathrm{~mm}, 75 \%$ (198/265) waren nodal negativ, außerhalb des Screenings lagen diese Raten bei $15 \%(79 / 546)$ bzw. bei $64 \%(322 / 503)$. Die Verteilung der invasiven Tumorgrößen (pT-Kategorien) und des Nodalstatus unterschieden sich statistisch signifikant zwischen in und außerhalb des Screenings detektierten Karzinomen ( $p=0,005$ bzw. $\mathrm{p}=0,004$ ).

Schlussfolgerung: Es konnte epidemiologisch belegt werden, dass die Einführung eines populationsbezogenen Mammografie-Screening-Programms zu einem deutlichen Anstieg der altersspezifischen Brustkrebsinzidenz führt. Die Charakteristika der Screeningkarzinome erfüllen die Vorgaben der Europäischen Leitlinien und sind prognostisch günstiger als Mammakarzinome, die außerhalb des Screening-Programms diagnostiziert wurden. Damit bietet das digitale Mammografie-Screening die Voraussetzungen für eine effektive Früherkennung.

\section{Abstract \\ $\nabla$}

Purpose: To epidemiologically evaluate the impact of digital mammography screening on incidence rates and tumor characteristics for breast cancer.

Materials and Methods: The first German digital screening units in the clinical routine were evaluated during the implementation period by using data from the cancer registry to compare the incidence rate of breast cancers and prognostic characteristics. $74 \%$ of women aged $50-69$ within the region of Muenster/Coesfeld/Warendorf were invited between $10 / 2005$ and 12/2007 for initial screening; $55 \%$ participated $(\mathrm{n}=35961)$.

Results: In $2002-2004$ the average breast cancer incidence rate (per 100000) was 297.9. During the implementation of screening, the rate rose to 532.9 in 2007. Of the 349 cancers detected with screening, $76 \%(265 / 349)$ were invasive compared to $90 \%(546 / 608)$ of cases not detected with screening during the same period. $37 \%$ (97/265) of cancers detected in the screening program had a diameter of $\leq 10 \mathrm{~mm}$ and $75 \%(198 / 265)$ were nodenegative compared to $15 \%(79 / 546)$ and $64 \%$ (322/503), respectively, in cancers detected outside the screening program. The distribution of invasive tumor size (pT categories) and the nodal status differed with statistical significance between cancers detected in and outside the program ( $\mathrm{p}=0.005$ and $\mathrm{p}=0.004$, respectively).

Conclusion: Epidemiological data shows that the implementation of a population-based screening program led to a relevant increase in the age-specific breast cancer incidence rate. The characteristics of breast cancers detected in the screening program comply with the requirements of the European guidelines and are significantly favorable compared to tumors diagnosed outside the program. These findings indicate that digital mammography screening fulfills the requirements for an early tumor detection tool. 


\section{Introduction}

\section{$\nabla$}

The expected benefits of breast cancer screening in certain age groups are the early detection of breast cancer and the subsequent reduction in mortality rates while reducing the negative side-effects of treatment by detecting cancer at earlier stages when it is more responsive to less aggressive treatment [1]. Studies on the impact of mammography screening programs revealed that the breast cancer mortality reductions observed for these routine services were consistent with those observed in previous randomized trials, confirming a $25-39 \%$ decrease in breast cancer deaths in women over age 50 [2-4]. An observed decline in the rate of death from breast cancer could be explained by a combination of screening and improved therapy not by either alone [5].

To accomplish these goals, quality assured programs define a priori surrogate parameters serving as indicators for the targeted reduction in breast cancer mortality rates. Performance parameters, like the proportion of small invasive cancers as well as the stage distribution of screening detected cancers, are useful right from the start of a program and should be provided by screening units. Death rates, despite being the primary endpoint of an evaluation of the effect of early cancer detection, delay the availability of program evaluation results by years because extended time periods are required for their conclusive assessment.

In 2002, the German Parliament decided to implement a national population-based mammography screening program. The German Radiation Protection Council agreed to the use of both digital and analog mammography technologies, but it required the specific evaluation of screening units using digital technology to make sure that the quality of digital mammography is not inferior to film mammography screening.

In October 2005, the first two digital screening units in Germany began operation. We previously reported on the performance indicators after one year of digital screening and showed that the parameters of the European guidelines were met at lower radiation levels than in screen film mammography [6].

The purpose of the present study was to evaluate the incidence rates and tumor characteristics of breast cancers detected in and outside the screening program for the region covered by these two digital screening units. To our knowledge this is the first epidemiological analysis of digital routine mammography screening in Germany.

\section{Materials und Methods}

$\nabla$

The national mammography screening program is based on the European guidelines [1, 7]. The target population includes all women between the ages of 50-69 years who are invited within the specified screening interval of two years.

The two screening units which form the basis of this report cover the geographic regions of Muenster, Coesfeld and Warendorf with a total population of 775973 inhabitants; 89025 belong to the target population of women in the age group of 50-69 years. The study period lasted from the onset of the screening program in October 2005 to the end of December 2007, thus encompassing the initial implementation phase of the program. Of the 65628 women invited according to the postal code of their places of residence during the study period $(73.7 \%$ of the total target population), 35961 women attended the screening examination (participation rate 55\%).

Both screening units performed mammography exclusively with digital techniques (MicroDosis Mammography, MDM, Sectra Medical Systems; Mammomat 3000 Nova, Siemens Healthcare, DirectView CR975 EHR-M2, Carestream Health; Mammomat 3000 Nova, Siemens Healthcare, FCR Profect CS, Fuji and Senographe DMR+, General Electric with DirectView CR975, Carestream Health). All devices fulfill the national requirements (PAS 1054) as well as the requirements for contrast resolution of EPQC (European Protocol for the Quality Control of the Physical and Technical Aspects of Mammography Screening) [8].

The mammograms were double read (softcopy reading). To resolve discrepancies between the interpretations of the two readers review by consensus including a third reader was mandatory. The assessment was organized in a centralized way by the screening units [7]. Before undergoing mammography, the participating women gave written informed consent to the management of their personal data for internal quality assurance procedures of the screening units.

The Epidemiological Cancer Registry for the State of North Rhine-Westphalia (EKR NRW) comprises the geographic regions of Muenster, Coesfeld and Warendorf. Breast cancer reports reach the EKR NRW from pathology institutes in the region and from hospitals treating breast cancer patients. The EKR NRW receives notifications only by electronic means and stores all data exclusively under pseudonyms, i.e., as doubly encrypted personal identifying data. The EKR NRW has been certified by the national Robert-Koch Institute as providing complete registration of breast cancer cases in the Muenster region since the late $1990 \mathrm{~s}$. For the purpose of this report, all personal data from the screening units were transformed into pseudonyms which were then used for record linkage within the EKR [9]. Cases of breast cancer originating from the two screening units were specifically tagged in the registry database. Record linkage identified cases detected in the screening program for which additional notifications from other sources existed but we used only the data provided by the screening units for our analyses. As a result, we were able to distinguish between breast cancer cases which were detected within the mammography screening program and cases detected outside the screening program. Only cases after therapeutic surgery were included.

We compared the breast cancer incidence rates before (2002 2004) and after the onset of the digital population-based screening program (October 2005 - December 2007). We analyzed prognostic characteristics including tumor size, lymph node involvement, and histopathological grading for cancers diagnosed before and after the onset of the screening program in the same target population. The data were evaluated by means of the chi square test.

\section{Results \\ $\nabla$}

In the time period preceding the mammography screening program, the average breast cancer incidence rates per 100000 women aged 50-69 years in the study region rose from 225.2 in $1993-1995$ to 297.9 in $2002-2004$. The proportion of invasive cancers (ICD-10: C50) in 2002-2004 was 93\% and that of ductal carcinoma in situ (DCIS; ICD-10: D05) was 7\%. 


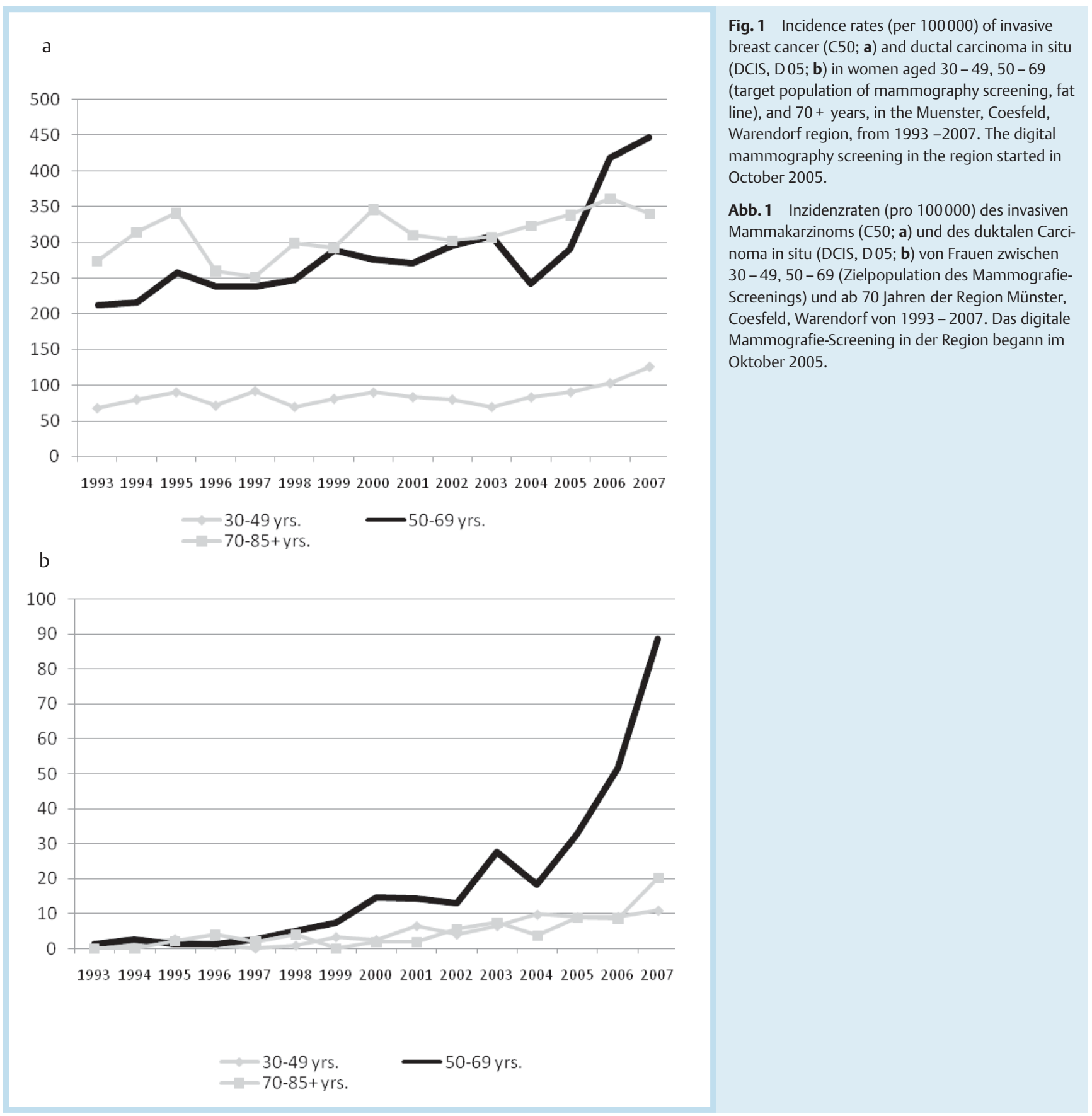

With the onset of mammography screening, the breast cancer incidence rate in the target population increased from 320.8 in 2005 to 467.6 in 2006 and 532.9 per 100000 women in 2007. The respective incidence rates for invasive breast cancer were 290.3 (2005), 418.4 (2006) and 446.5 (2007) ( Fig. 1). The regionalized time analysis shows an increase in the breast cancer incidence rate in association with the local successive increase in invitations to the program ( Fig. 2 ).

The average number of breast cancer cases in 2002-2004 among women 50 -69 years old in the region was 263 per year. After the onset of the screening program, the annual number of newly diagnosed breast cancers in this age group rose to 412 in 2006 and to 477 in 2007. The median age of women with breast cancer was 61 years in cases detected before the start of the mammography screening program, 60 years among cases detected outside the screening program and 62 years among cases detected in the screening program during the implementation phase.

The overall cancer detection rate of initial digital screening examinations was $0.98 \%$ (354/35961) with a recall rate of $6.89 \%$ (2478/35961). Record linkage with the cancer registry resulted in exclusion of 5 women who resided outside the defined target region (self-invited) or who were older than 69 years at the time of diagnosis, leaving 349 breast cancer cases detected in the screening program for this evaluation. For $96 \%$ of women, the database of the cancer registry also contained notifications from other sources. In the same time period 608 cases of breast cancer detected outside the screening program were identified in the registry. 


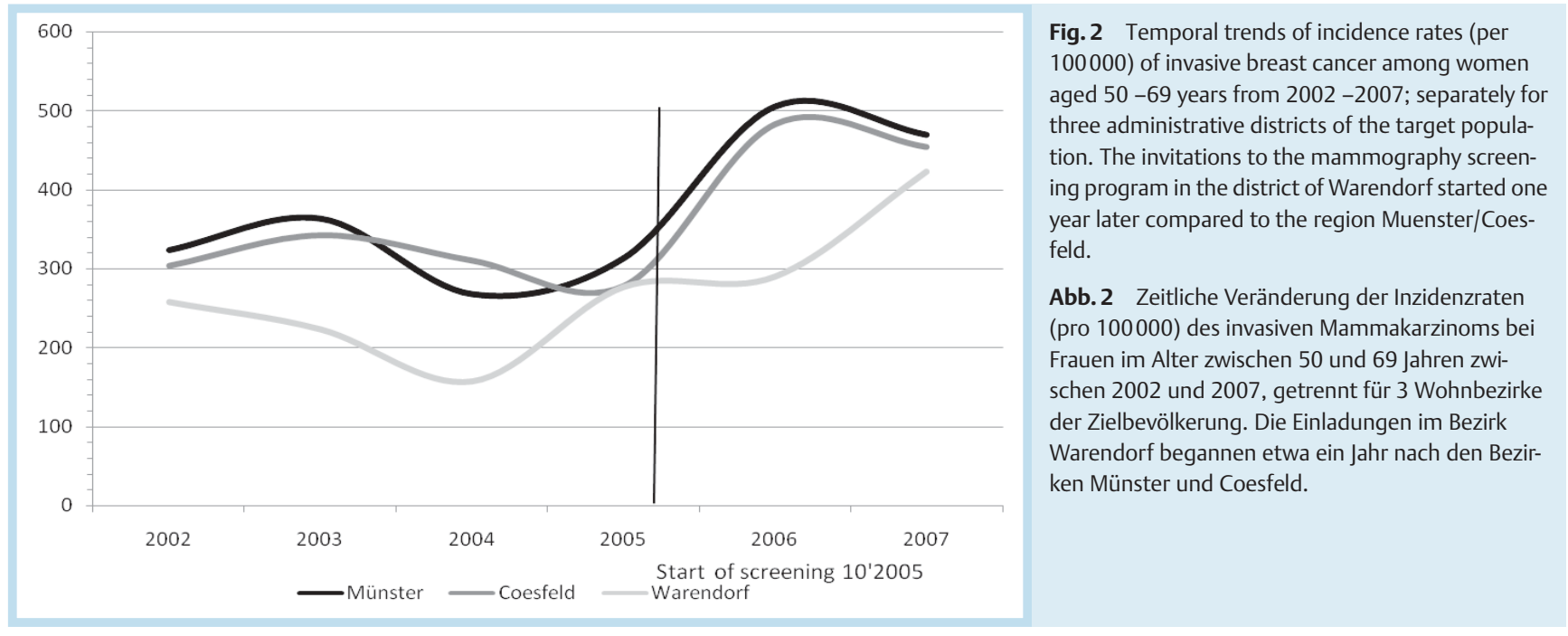

\begin{tabular}{|c|c|c|c|c|c|c|c|}
\hline & 2002 & & $10 / 2$ & |2007 & & & \\
\hline & $\begin{array}{l}\text { brea } \\
\text { befo } \\
\text { scre }\end{array}$ & $\begin{array}{l}\text { cers } \\
t \text { of }\end{array}$ & $\begin{array}{l}\text { brea } \\
\text { outs } \\
\text { pros }\end{array}$ & $\begin{array}{l}\text { s detected } \\
\text { e screening }\end{array}$ & $\begin{array}{l}\text { brea } \\
\text { dete } \\
\text { scre }\end{array}$ & $\begin{array}{l}\text { ers } \\
\text { the } \\
\text { rogram }\end{array}$ & \\
\hline & n & $\%$ & $n$ & $\%$ & n & $\%$ & p-value ${ }^{1}$ \\
\hline DCIS (D05) & 51 & 7.2 & 62 & 10.2 & 84 & 24.1 & $<0.001$ \\
\hline invasive cancers (C50) & 737 & 92.8 & 546 & 89.8 & 265 & 75.9 & \\
\hline -Tmic & 5 & 0.7 & 6 & 1.0 & 1 & 0.3 & \\
\hline$-\mathrm{T} 1 \mathrm{a}$ & 26 & 3.7 & 23 & 3.9 & 27 & 7.7 & \\
\hline$-\mathrm{T} 1 \mathrm{~b}$ & 74 & 10.4 & 50 & 8.4 & 69 & 19.8 & \\
\hline$-\mathrm{T} 1 \mathrm{c}$ & 246 & 34.6 & 216 & 36.4 & 116 & 33.2 & \\
\hline$-\mathrm{T} 1$ & 11 & 1.6 & 12 & 2.0 & - & - & \\
\hline$-\mathrm{T} 2$ & 219 & 30.8 & 170 & 28.6 & 45 & 12.9 & \\
\hline$-\mathrm{T3}$ & 41 & 5.8 & 31 & 5.2 & 5 & 1.4 & \\
\hline$-\mathrm{T} 4$ & 33 & 4.6 & 17 & 2.9 & 2 & 0.6 & 0.005 \\
\hline$-T x$ & 5 & 0.7 & 6 & 1.0 & - & - & \\
\hline missing & 77 & & 15 & & . & & \\
\hline$-\mathrm{N}-$ & 374 & 57.4 & 322 & 61.2 & 198 & 74.7 & \\
\hline$-\mathrm{N}+$ & 258 & 39.6 & 181 & 34.4 & 67 & 25.3 & 0.004 \\
\hline$-N x$ & 20 & 3.1 & 23 & 4.4 & - & - & \\
\hline missing & 85 & & 20 & & - & & \\
\hline
\end{tabular}

Table 1 Distribution of tumor categories and nodal status of breast cancers detected before start of screening $(2002-2004)$ and after start of screening (10/2005 - 12 / 2007). For the latter, cases detected in and outside of the screening program are reported separately.

Tab. 1 Verteilung der Tumorkategorien und des Nodalstatus der Mammakarzinome detektiert vor dem Start des Screenings (2002 2004) und nach dem Start des Screenings (10/2005 - 12/2007). Für den Zeitraum ab dem Screeningstart erfolgte eine Aufteilung in innerhalb und außerhalb des Screening-Programms detektierter Fälle.

${ }^{1}$ Comparison of cases detected in and outside of the screening program by chi-square test.

- Table 1 compares the tumor staging of breast cancer cases according to calendar time and occasion of detection. It reveals that $76 \%$ (265/349) of the breast cancers detected in the screening program were invasive and that $24 \%$ (84/349) were DCIS. $37 \%$ (97/265) of invasive cancers detected in the screening program measured $\leq 10 \mathrm{~mm}$ (pTmic, pT1a, pT1b) and 75\% (198/ 265) were node-negative. By comparison, among the cases detected outside the screening program of the same period and target population, 90\% (546/608) were invasive breast cancers, and $10 \%(62 / 608)$ were DCIS. The respective proportion of invasive cancers $\leq 10 \mathrm{~mm}$ (pTmic, pT1a, pT1b) was $15 \%(79 / 546)$ and that of the node-negative invasive breast cancers was $64 \%$ (322/503). The difference in the distribution of tumor categories and rate of node-negative invasive cancers between these two groups was highly statistically significant ( $\bullet$ Table 1 ). In contrast, the tumor stages in breast cancer cases occurring before the start of the mammography screening program were similarly distributed as the cases detected outside the screening program after the program start.

Due to incomplete documentation of the distant metastasis status, the tumor stage (UICC) could not be assessed for 6 cancers detected in the screening program (2\%) and for 116 cancers detected outside of the screening program (19\%). Assuming that missing observations occurred at random, cancers detected in the screening program showed a rate of UICC stage II and higher (II +) of $25 \%(86 / 343)$ as compared to $47 \%$ (232/ $492)$ in the cancers detected outside the screening program.

With regard to the histopathological grading, the proportion of grade 3 invasive breast cancers was higher in the period before screening onset and among cases detected outside the screening program while it was lower in cases detected in the screening program. By contrast, the proportion of grade 1 cancers was substantially higher in the cases detected in the screening program than in cases detected outside the screen- 


\begin{tabular}{|c|c|c|c|c|c|c|c|}
\hline & \multicolumn{2}{|c|}{$2002-2004$} & \multicolumn{4}{|c|}{$10 / 2005-12 / 2007$} & \\
\hline & \multicolumn{2}{|c|}{$\begin{array}{l}\text { breast cancers } \\
\text { before start of } \\
\text { screening }\end{array}$} & \multicolumn{2}{|c|}{$\begin{array}{l}\text { breast cancers detected } \\
\text { outside of the screening } \\
\text { program }\end{array}$} & \multicolumn{2}{|c|}{$\begin{array}{l}\text { breast cancers } \\
\text { detected in the } \\
\text { screening program }\end{array}$} & \\
\hline & $\mathbf{n}$ & $\%$ & $\mathbf{n}$ & $\%$ & $\mathbf{n}$ & $\%$ & p- value ${ }^{2}$ \\
\hline \multicolumn{8}{|c|}{ invasive cancers (C50) } \\
\hline$-\mathrm{G} 1$ & 76 & 10.9 & 90 & 16.9 & 70 & 26.4 & \\
\hline$-G 2$ & 449 & 64.4 & 305 & 57.1 & 143 & 54.0 & \\
\hline$-G 3$ & 172 & 24.7 & 139 & 26.0 & 52 & 19.6 & 0.02 \\
\hline missing & 40 & & 12 & & & & \\
\hline \multicolumn{8}{|c|}{ DCIS (D05) } \\
\hline$-\mathrm{G} 1$ & 10 & 40.0 & 15 & 29.4 & 22 & 26.8 & \\
\hline$-G 2$ & 8 & 32.0 & 19 & 37.3 & 27 & 32.9 & \\
\hline$-G 3$ & 7 & 28.0 & 17 & 33.3 & 33 & 40.2 & 0.72 \\
\hline missing & 26 & & 11 & & 2 & & \\
\hline
\end{tabular}

Table 2 Histopathological grading of invasive and intraductal in-situ tumors detected in the screening program and outside of the screening program.

Tab. 2 Histopathologisches Grading invasiver und intraduktaler In-situ-Karzinome diagnostiziert innerhalb und außerhalb des Screening-Programms.

${ }^{1}$ Comparison of cases detected in and outside of the screening program by chi-square test.

ing program and to cancers diagnosed before screening onset. The differences in grading between cancers detected in and outside of the screening program were statistically significant ( Table 2).

Differences in grading levels observed for DCIS pointed in the opposite direction, showing more grade 3 cancers in DCIS detected in the screening program. However, these differences were not statistically significant ( Table 2$)$.

\section{Discussion}

The implementation of the digital mammography screening program in two screening units in NRW was accompanied by a substantial regional increase in the breast cancer incidence rates in women aged 50-69 years. The increase in incidence rates was seen for both invasive cancer and ductal carcinoma in situ. In accordance with the European guidelines, the average detection rate in the initial screening round exceeded the desirable level $(>3 \times$ expected incidence rate in the absence of screening, $>0.81 \%$ ) in both screening units. The increase in incidence rates parallels the incremental invitation of women in the target population to attend the screening program which led to consistently rising attendance numbers over the implementation phase despite fairly constant participation rates.

This is the first epidemiological report covering the time after the onset of the national mammography screening program focusing on screening units that employ exclusively digital techniques. In the pre-screening period, the local cancer registry provided a baseline breast cancer incidence rate that was used for comparison. During the implementation phase of the screening program, notifications of breast cancers were sent to the cancer registry by the screening units and, concurrently, by pathology institutes and hospitals in the region.

Our assessment of the implementation of digital screening in the two screening units confirms that the required standards for prognostic parameters of the European guidelines were clearly met. Moreover, an increase in the total breast cancer incidence rate - specifically in the age group of 50-69 years, an expected epidemiological indicator - was observed. This happened with an invitation rate of $74 \%$ in the evaluated time period since one mammography unit could start only one year later. The participation rate in this new program for the region was $55 \%$. The prevalence round was completed in 2008. Regionalized time analyses of our data confirm the conclusion that our observations show a direct screening impact which is not explained by other potential effects such as concurrently intensified opportunistic screening.

Various studies described an increase in breast cancer incidence rates in the last two to three decades for situations both with and without organized mammography screening $[10,11]$. Where organized screening has been introduced, this increase is more marked, mainly as a result of the additional detection of prevalent early breast cancer stages. Previous studies confirm that the initial, but temporary, significant increase in the breast cancer incidence rate is followed by a significant decrease in advanced diseases in the women invited for screening [12]. It is important to realize that the initial increase does not indicate over-diagnosis, but that it is the result of the down-staging of breast cancer diagnoses necessary for screening effectiveness.

The characteristics of the cancers detected in the screening program comply fully with the parameters defined by the European guidelines [1] concerning the desirable proportions of small invasive cancers, of node-negative cancers and the maximum proportions of patients with advanced tumor stages (UICC stage II and higher). In particular, the proportion of $37 \%$ for small invasive cancers less than or equal to $10 \mathrm{~mm}$ clearly exceeded the desirable level of $25 \%$ set by the European guidelines for initial screening rounds. In contrast, breast cancers detected in the same period and population outside of the screening as well as diagnosed before the program start included substantially more tumors $>10 \mathrm{~mm}$, node-positive cancers and more advanced UICC stages. It should be remembered that breast cancers detected outside the screening program represent a mixture of cases that consist of symptomatic cancers and cancers detected through unorganized surveillance among women not yet invited to or not participating in the mammography screening program, or interval cancers.

Histopathological grading according to the Nottingham system is a generally accepted strong prognostic factor, even for tumors less than or equal to $10 \mathrm{~mm}$ [13]. We analyzed the histological grade distribution. Compared to tumors diagnosed outside of the screening program, grade 1 was more common among invasive cancers detected in the screening program 
(26 vs. 17\%). It is often critically commented that screening detects many low grade invasive cancers with a frequently excellent prognosis and it is argued that such tumors may never have presented clinically or been life-threatening. On the other hand, a proportion of grade 1 invasive carcinomas may dedifferentiate over time into more aggressive grade 2 and 3 tumors $[14,15]$. Here, screening may lead to the identification and removal of such tumors when they are still low grade and potentially interrupt the progression to high grade tumors. Detection at a small size with a low histological grade may thus help avoid the risk of lymph node metastasis associated with subsequent large grade 3 carcinomas.

For digital screening, generally higher DCIS rates are reported compared to analogous film screening. The DCIS rate of $24 \%$ in this report is in line with previous reports [16]. The optimal proportion of DCIS in a screening program is the subject of an ongoing debate. Some authors have described DCIS as the main cause for over-diagnosis and over-treatment [17]. Others, analyzing randomized mammography screening trials estimated that less than $5 \%$ of DCIS diagnosed during prevalence screening are being over-diagnosed [18]. Based on clinical follow-up reports, the overall progression of DCIS to invasive malignancy has been reported to range from $14-75 \%$ [19]. These percentages may represent underestimates because most of the respective data come from originally misdiagnosed DCIS. Although there is obviously limited knowledge of what exact proportion of DCIS will progress into invasive cancer, it seems to be clear that such progress is believed to be faster with grade 3 DCIS [20]. In our study, $40 \%$ of the DCIS cases detected in the screening population were grade 3. This means that cases of DCIS detected by digital mammography screening are more often higher grade than those detected outside the screening program (33\%). With respect to molecular and conventional pathology, there is no doubt that high grade DCIS gives rise to high grade invasive cancer while low grade DCIS gives rise to low grade invasive cancer. Preventing such high grade invasive diseases will probably have a considerable impact on breast cancer mortality [2-4]. The proportion of grade 1 DCIS lesions within the screening group does not differ significantly from that outside screening (27 vs. 29\%) suggesting no preferential detection of low grade DCIS. Probably the trends toward DCIS grade 3 in cancers detected in the screening program represents a more standardized way [21] of assessing microcalcifications compared to unorganizised surveillance supposing that pure DCIS is of less importance in symptomatic patients.

\section{Conclusion \\ $\nabla$}

The results of the first two years of digital mammography screening in the region of Muenster, Coesfeld, Warendorf indicate that relevant quality parameters were in good agreement with requirements of the European guidelines. After invitation of about $75 \%$ of all women in the age group of 50 to 69 years, we observed a marked increase in breast cancer incidence rates in the target population. These results indicate an effective performance of digital mammography screening with high quality.

\section{Acknowledgement}

$\nabla$

The authors acknowledge the effort of both screening teams Münster-Süd/Coesfeld: S. Spital, R. Hovestadt, M. Göb, G. Hötte, E. Schmidt-Eversheim and Münster-Nord/Warendorf: W. Heindel, S. Weigel, B. Dechant, I. Henseleit, B. Kirchner.

We acknowledge the support of D. Berning, J. Czwoydzinski, R. Girnus, H. Lenzen, S. Michalk, A. Sommer (Reference Center Münster) and of K. Kraywinkel (Epidemiological Cancer Register NRW) for data management.

\section{References}

1 Perry NM, Broeders $M$, de Wolf C et al. European Guidelines for Quality Assurance in Breast Cancer Screening and Diagnosis. Luxembourg: Office for Official Publications of the European Communities, 2006; $4^{\text {th }}$ ed

2 International Agency for Cancer research, Effectiveness of screening. Breast cancer screening Lyon, France: IARC Press, 2002: 119-156

3 The Swedish Organised Service Screening Evaluation Group. Reduction in breast cancer mortality from organized service screening with mammography: 1. Further confirmation with extended data. Cancer Epidemiol Biomarkers Prev 2006; 15: 45-51

4 The Swedish Organised Service Screening Evaluation Group. Reduction in breast cancer mortality from the organised service screening with mammography: 2. Validation with alternative analytic methods. Cancer Epidemiol Biomarkers Prev 2006; 15: 52-56

5 Berry DA, Cronin KA, Plevritis SK et al. Effect of screening and adjuvant therapy on mortality from breast cancer. N Engl J Med 2005; 353: 1784-1792

6 Weigel S, Girnus R, Czwoydzinski J et al. Digital mammography screening: average glandular dose and first performance parameters. Fortschr Röntgenstr 2007; 179: 892-895

7 Bundesmantelvertrag - Ärzte/Ersatzkassen über besondere Versorgungsaufträge im Rahmen des Programms zur Früherkennung von Brustkrebs durch Mammographie-Screening. Anlage 9.2 Versorgung im Rahmen des Programms zur Früherkennung von Brustkrebs durch Mammographie-Screening. Deutsches Ärzteblatt 2004; 4: 16-44

8 Sommer A, Girnus R, Wendt B et al. Physikalisch-technische Qualitätssicherung im deutschen Mammografie-Screening-Programm: Erfahrungsbericht des Referenzzentrums Münster nach drei Jahren. Fortschr Röntgenstr 2009; 181: 447-453

9 Krieg V, Hense HW, Lehnert $M$ et al. Record linkage mit verschlüsselten Identifikationsdaten in bevölkerungsbezogenen Krebsregistern. Entwicklung, Implementierung und Fehlerraten. Gesundheitswesen 2001; 63: 376-382

10 Buiatti E, Barchielli A, Bartolacci S et al. SCREENREG Working Group. The impact of organised screening programmes on the stage-specific incidence of breast cancer in some Italian areas. Eur J Cancer 2003; 39: $1776-1782$

11 de Gelder R, Bulliard JL, de Wolf C et al. Cost-effectiveness of opportunistic versus organised mammography screening in Switzerland. Eur J Cancer 2009; 45: 127-138

12 Fracheboud J, Otto SJ, van Dijck JA et al. National Evaluation Team for Breast cancer screening (NETB). Decreased rates of advanced breast cancer due to mammography screening in The Netherlands. Br J Cancer 2004; 91: 861-867

13 Rakha EA, El-Sayed ME, Lee AHS et al. Prognostic Significance of Nottingham Histologic Grade in Invasive Breast Carcinoma. J Clin Oncol 2008; 26: 3153-3158

14 Bucchi L, Barchielli A, Ravaioli A et al. Screen-detected vs clinical breast cancer: the advantage in the relative risk of lymph node metastases decreases with increasing tumour size. Br J Cancer 2005; 92: 156-161

15 Tabar L, Fagerberg G, Chen HH et al. Tumour development, histology and grade of breast cancers: prognosis and progression. Int J Cancer 1996; 66: 413-419

16 Pisano ED, Gatsonis C, Hendrick E et al. Diagnostic Performance of Digital versus Film Mammography for Breast-Cancer Screening. N Engl J Med 2005; 353: 1773-1783

17 Paci E, Warwick J, Falini P et al. Overdiagnosis in screening: is the increase in breast cancer incidence rates a cause for concern? J Med Screen 2004; 11: 23-27

18 Duffy SW, Agbaje O, Tabar L et al. Overdiagnosis and overtreatment of breast cancer: estimates of overdiagnosis from two trials of mammo- 
graphic screening for breast cancer. Breast Cancer Res 2005; 7: 258265

19 Leonard GD, Swain SM. Ductal Carcinoma In Situ, Complexities and Challenges. J Natl Cancer Inst 2004; 96: 906-920

20 Badve S, A'Hern RP, Ward AM et al. Prediction of local recurrence of ductal carcinoma in situ of the breast using five histological classifica- tions: a comparative study with long follow-up. Hum Pathol 1998; 29 : 915-923

21 Müller-Schimpfle M. Konsensustreffen der Kursleiter in der Mammadiagnostik am 5.5.2007 in Frankfurt am Main, Thema Mikrokalk. Fortschr Röntgenstr 2008; 180: 66-68 